\title{
Synthesis, spectroscopic characterization and catalytic activity of platinum(II) carbene complexes
}

\author{
Ekaterina Bolbat $^{\mathrm{a}}$, Karina Suarez-Alcantara ${ }^{\mathrm{b}}$, Sophie E. Canton ${ }^{\mathrm{c}, \mathrm{d}}$, Ola F. Wendt ${ }^{\mathrm{a}, *}$ \\ ${ }^{a}$ Centre for Analysis and Synthesis, Department of Chemistry, Lund University, P.O. Box 124, S-221 00 Lund, Sweden \\ ${ }^{\mathrm{b}}$ Unidad Morelia del Instituto de Investigaciones en Materiales, Universidad Nacional Autónoma de México, Antigua Carretera a Pátzcuaro No. 8701, \\ Col. Ex Hacienda de San José de la Huerta, CP 58190 Morelia, Michoacán, Mexico \\ ${ }^{\mathrm{c}}$ FS-SCS, Deutsches Elecktronen-Synchrotron (DESY), Notkestr.85, 22607 Hamburg, Germany \\ ${ }^{\mathrm{d}}$ Max Planck Institute for Biophysical Chemistry, Am Fassberg 11, 37077 Göttingen, Germany
}

\section{A R T I C L E I N F O}

\section{Article history:}

Received 17 December 2015

Received in revised form 16 February 2016

Accepted 18 February 2016

Available online 26 February 2016

\section{Keywords:}

NHC carbene complexes

Platinum

EXAFS

XRD

Hydrosilylation

\begin{abstract}
A B S T R A C T
A novel platinum complex with 1,3-bis(2,6-diisopropylphenyl)-1,3-dihydro-2H-imidazol-2-ylidenyl ligand has been synthesized and characterized on the basis of elemental analysis, MS, ${ }^{1} \mathrm{H}$ and ${ }^{13} \mathrm{C}$ NMR spectroscopy, X-ray Absorption Spectroscopy and single crystal X-ray diffraction studies. The XRD determination of the complex (monoclinic, $C 2 / c$ ) revealed a structure in which the platinum (II) centre coordinates two chlorides, a carbon atom of the N-heterocyclic carbene (NHC) and is stabilized by coordinating the nitrogen atom of a 3-chloropyridine molecule, forming an over-all square planar geometry. By prolonging the time of the reaction, it was possible to obtain the trans-dichloridobis(3-chloropyridine) platinum(II) complex under the same reaction conditions. The electronic and molecular properties of both complexes were investigated and compared by means of Near Edge X-ray Absorption Fine Structure spectroscopy (NEXAFS), supported by numerical simulations. The platinum carbene complex obtained was tested in a series of $\mathrm{C}-\mathrm{H}$ activation and hydrosilylation reactions.
\end{abstract}

(c) 2016 Elsevier B.V. All rights reserved.

\section{Introduction}

Over the last decade $\mathrm{N}$-heterocyclic carbene complexes of late transition metals have gained significant attention in modern chemistry due to their truly unique features [1-5]. These compounds are widely utilized across the chemical field including the use in materials [6,7], as metallopharmaceuticals [8-10] and extensively as both homogeneous and heterogeneous catalysts [11-15]. Among them is a family of catalytically active so-called PEPPSI-complexes wherein a palladium(II) centre is strongly coordinating an NHC ligand and is stabilized by 3-chloropyridine as an ancillary ligand [16-18]. First synthesized by Organ and co-workers, these complexes have been shown to possess spectacular reactivity in a range of cross coupling reactions such as Suzuki-Miyaura [19-21], Negishi [22-24], Buchwald-Hartwig [25-28] and Kumada reactions [29].

Compared to the extensive coordination chemistry of palladium-NHC compounds, similar platinum complexes have been much less studied until the recent discovery of their high anticancer activity [30-33]. However, interactions of Pt-NHC with biological systems and their therapeutic properties remain a substantially unexplored field of great interest [34]. Similarly,

\footnotetext{
* Corresponding author.
}

Pt-NHC complexes have considerable potential for use in catalysis, e.g. hydrosilylation, cycloisomerization, $\mathrm{C}-\mathrm{H}$ activation processes, etc [35-38]. Thus, the development of novel Pt complexes with a diverse range of NHC ligands is in high demand. In the present work, we report the first PEPPSI type Pt complex together with its catalytic activity in $\mathrm{C}-\mathrm{H}$ functionalization and hydrosilylation reactions.

A general trend to extend and significantly improve the application of transition metal complexes, including Pt carbene compounds, is the creation of hybrid materials where metal complexes are covalently grafted to a suitable kind of support such as organic polymers, metal oxides, nanotubes or plastics [39-42]. Despite the many benefits of such method, the main drawback arises from the lack of analytical techniques for characterization of the obtained materials. For such hybrids, it is important to monitor closely the initial stability, the changes in oxidation state, and the nature of the chemical bonding during the activation step in order to optimize these systems. In this regard, the near edge region of the X-ray absorption (XA) spectrum is an extremely sensitive probe of the electronic and structural properties around a specific metal centre for samples in any physicochemical phase of matter, unlike X-ray diffraction that relies on longrange crystalline ordering. In this study, we introduce the comparative analysis of electronic and structural properties of 
[1,3-bis(2,6-diisopropylphenyl)imidazol-2-ylidene](3-chloropyridine) platinum(II) dichloride and trans-dichlorobis(3-chloropyridine) platinum(II) complexes using a combination of XRD and XAS techniques. This gives a convenient reference material when using such compounds in the study of catalysis mechanisms.

\section{Experimental}

\subsection{General considerations}

Commercially available reagents and deuterated solvents were purchased from Sigma Aldrich and Acros Organics and used as received. 1,3-Bis(2,6-diisopropylphenyl)imidazolium chloride was prepared according to the previously published procedure [43]. ${ }^{1} \mathrm{H}$ and ${ }^{13} \mathrm{C}$ NMR spectra were recorded on a Bruker Avance 400 spectrometer working at $400 \mathrm{MHz}$. Chemical shifts are given in ppm downfield from TMS using residual peak of the solvents as a reference. Multiplicities are abbreviated as follows: (s) singlet, (d) doublet, (t) triplet, ( $\mathrm{m}$ ) multiplet. Elemental analysis were performed by H. Kolbe Mikroanalytisches Laboratorium, Mülheim an der Ruhr, Germany. IR spectra were recorded on a Bruker Alpha spectrometer, with diamond ATR-FT IR detection.

\subsection{Synthesis of [1,3-bis(2,6-diisopropylphenyl)imidazol-2-ylidene] (3-chloropyridyl)-platinum(II) dichloride (1)}

Platinum(II) chloride $(0.150 \mathrm{~g}, 0.564 \mathrm{mmol}), 1,3$-Bis(2,6-diisopropylphenyl)imidazolium chloride $(0.264 \mathrm{~g}, 0.621 \mathrm{mmol})$ and $\mathrm{K}_{2} \mathrm{CO}_{3}(0.389 \mathrm{~g}, 2.81 \mathrm{mmol})$ were added to $2.25 \mathrm{~mL}$ of 3-chloropyridine in a $4 \mathrm{ml}$ vial capped with a Teflon-lined screw cap. The resulting mixture was vigorously stirred for $48 \mathrm{~h}$ at $80^{\circ} \mathrm{C}$. After cooling to RT, the reaction mixture was diluted with dry dichloromethane and filtered through a short pad of Celite. The solvent was removed on the high vacuum line and the crude was stirred in dry $\mathrm{n}$-pentane during the night. The beige residue was separated by decanting the liquid and purified with column chromatography (eluent: $n$-hexane:ethyl acetate $=8: 9$ ). The solvent was evaporated and the yellow-orange solid was dried in high vacuum $(0.317 \mathrm{~g}$, 73\%). ${ }^{1} \mathrm{H}$ NMR (400 MHz, $\left.\mathrm{CD}_{2} \mathrm{Cl}_{2}\right): \delta[\mathrm{ppm}]=8.63(\mathrm{~d}, 1 \mathrm{H}), 8.56$ (dd, 1H), $7.67(\mathrm{dt}, 1 \mathrm{H}), 7.49(\mathrm{dd}, 1 \mathrm{H}), 7.34(\mathrm{~d}, 4 \mathrm{H}), 7.15(\mathrm{dd}, 1 \mathrm{H})$, $7.12(\mathrm{~s}, 2 \mathrm{H}), 3.14(\mathrm{~m}, 4 \mathrm{H}), 1.42(\mathrm{~d}, 12 \mathrm{H}), 1.11(\mathrm{~d}, 12 \mathrm{H}) .{ }^{13} \mathrm{C}$ NMR $\left(101 \mathrm{MHz}, \mathrm{CDCl} 3,25^{\circ} \mathrm{C}\right): \delta[\mathrm{ppm}]=150.5,149.5,146.6,137.5$, $135.4,132.5,130.2,128.0,126.0,124.9,124.3,124.0,29.9,28.8$, 26.4, 23.1. Anal. Calc. for $\mathrm{C}_{32} \mathrm{H}_{40} \mathrm{Cl}_{3} \mathrm{~N}_{3} \mathrm{Pt}$ : C, 50.04; $\mathrm{H}, 5.25$; N, 5.47. Found: C, 50,24; H, 5,91; N, 5,12\%.

\subsection{Synthesis of trans-dichlorobis(3-chloropyridine) platinum(II) (2)}

Platinum(II) chloride $(0.100 \mathrm{~g}, 0.376 \mathrm{mmol}), 1,3$-bis(2,6-diisopropylphenyl) imidazolium chloride $(0.176 \mathrm{~g}, 0.414 \mathrm{mmol})$ and $\mathrm{K}_{2} \mathrm{CO}_{3}(0.214 \mathrm{~g}, 1.54 \mathrm{mmol})$ were added to $1.5 \mathrm{~mL}$ of 3-chloropyridine in a $4 \mathrm{ml}$ vial capped with a Teflon-lined screw cap. The resulting mixture was vigorously stirred for $64 \mathrm{~h}$ at $80^{\circ} \mathrm{C}$. After cooling to RT, the reaction mixture was diluted with dry dichloromethane and filtered through a short pad of silica gel covered with a pad of Celite eluting with $\mathrm{CH}_{2} \mathrm{Cl}_{2}$ until the product was completely recovered. The solvent was removed on the high vacuum line and the crude was stirred in dry n-pentane during the night. The residue was separated by decanting the liquid and purified with column chromatography (eluent: n-hexane:ethyl acetate $=1: 10$ ). The solvent was evaporated and a yellow solid was dried in high vacuum $(0.060 \mathrm{~g}, 32 \%)$.

${ }^{1} \mathrm{H} \mathrm{NMR}\left(400 \mathrm{MHz}, \mathrm{CD}_{2} \mathrm{Cl}_{2}\right): \delta[\mathrm{ppm}]=8.98(\mathrm{~s}, 2 \mathrm{H}), 8.86(\mathrm{~d}, 2 \mathrm{H})$, $7.89(\mathrm{~d}, 2 \mathrm{H}), 7.36(\mathrm{t}, 2 \mathrm{H})$. A preliminary XRD data set was recorded and shown to be in accordance with the literature [44].

\subsection{General procedure for the $\mathrm{C}-\mathrm{H}$ acetoxylation of 4-(2-pyridyl) benzaldehyde}

4-(2-Pyridyl)benzaldehyde ( $25 \mathrm{mg}, 0.137 \mathrm{mmol}, 1$ equiv), $\mathrm{PhI}$ $(\mathrm{OAc})_{2}$ (54.3 $\mathrm{mg}, 0.164 \mathrm{mmol}, 1.2$ equiv), and the Pt-IPr catalyst (5.2 $\mathrm{mg}, 0.007 \mathrm{mmol}, 0.05$ equiv) were combined in $\mathrm{CH}_{3} \mathrm{CN}$ $(2 \mathrm{~mL})$ in a $8 \mathrm{~mL}$ vial. The vial was sealed with a Teflon lined cap, and the reaction mixture was heated at $100^{\circ} \mathrm{C}$ for $24 \mathrm{~h}$. The reaction mixture was analyzed by GC.

\subsection{General procedure for the hydrosilylation of styrene}

A Straus flask was charged with styrene $(0.416 \mathrm{~g}, 4 \mathrm{mmol}, 1$ equiv), bis(trimethylsiloxy)methylsilane $(0.979 \mathrm{~g}, 4.4 \mathrm{mmol}, 1.1$ equiv) and the Pt-IPr catalyst ( $15.4 \mathrm{mg}, 0.02 \mathrm{mmol}, 0.005$ equiv) under an atmosphere of $\mathrm{N}_{2}$ and then was put on a preheated oil bath for $6 \mathrm{~h}$. For analysis, an aliquot $(0.1 \mathrm{~mL})$ was removed from the reaction mixture, diluted with deuterated chloroform in an NMR tube and analyzed by ${ }^{1} \mathrm{H}$ NMR spectroscopy.

\subsection{Single-crystal X-ray diffraction}

Single crystals suitable for X-ray analysis of complex 1 were grown from a concentrated solution by slow evaporation in chloroform. Intensity data were collected with an Oxford Diffraction Excalibur 3 system, using $\omega$-scans and Mo K $\alpha(\lambda=0.71073 \AA)$ radiation [45]. The data were extracted and integrated using Crysalis RED [46]. The structure was solved by direct methods and refined by full-matrix least-squares calculations on $F^{2}$ using SHELXTL5.1 [47]. Molecular graphics were generated using CrystalMaker $^{\circledR}$ 8.3.5. Crystallographic data and details of the data collection and structure refinements are listed in Table 1.

\subsection{X-ray Absorption Spectroscopy}

The X-ray Absorption Spectroscopy (XAS) experiments were carried out at the beamline I811 of the MAX-II storage ring in Lund, Sweden, operating at $1.5 \mathrm{GeV}$ with a current maximum at $250 \mathrm{~mA}$ (2 injections per day). This is a superconducting multipole wiggler beamline equipped with a water-cooled channel cut Si(111) double crystal monochromator delivering at $10 \mathrm{keV}$, approximately

Table 1

Crystal data and refinement details for compound $\mathbf{1 .}$

\begin{tabular}{|c|c|}
\hline Formula & $\mathrm{C}_{32} \mathrm{H}_{40} \mathrm{Cl}_{3} \mathrm{~N}_{3} \mathrm{Pt}$ \\
\hline Fw & 768.11 \\
\hline Space group & $C 2 / c$ \\
\hline Crystal system & monoclinic \\
\hline$T(\mathrm{~K})$ & 293 \\
\hline$a(\AA)$ & $34.0085(16)$ \\
\hline$b(\AA)$ & $15.9935(8)$ \\
\hline$c(\AA)$ & $12.7181(7)$ \\
\hline$\beta\left(^{\circ}\right)$ & $105.777(4)$ \\
\hline$V\left(\AA^{3}\right)$ & $6657.0(6)$ \\
\hline$Z$ & 8 \\
\hline$D_{\text {calcd }}\left(\mathrm{g} \mathrm{cm}^{-3}\right)$ & 1.533 \\
\hline$\mu\left(\mathrm{mm}^{-1}\right)$ & 4.481 \\
\hline$\theta$ range $\left(^{\circ}\right)$ & $2.487-28.881$ \\
\hline No. reflns collected & 13749 \\
\hline No. of unique reflns & 7501 \\
\hline$R(\mathrm{~F})(I>2(I))^{\mathrm{a}}$ & 0.0407 \\
\hline$w R^{2}\left(F^{2}\right)$ (all data $)^{\mathrm{b}}$ & 0.1133 \\
\hline$S^{\mathrm{c}}$ & 1.113 \\
\hline$R_{\text {int }}$ & 0.0394 \\
\hline $\mathrm{CCDC}$ & 1441883 \\
\hline
\end{tabular}


$2 \times 10^{15}$ photons/s/0.1\% bandwidth with horizontal and vertical FWHM of 7 and $0.3 \mathrm{mrad}$, respectively [48]. A beamsize of $0.5 \mathrm{~mm} \times 0.5 \mathrm{~mm}$ (width $\times$ height) was used. Samples were compacted in small pellets and fixed in the sample chamber at $45^{\circ}$ respective to the beam detector. The ionisation and sample chambers were filled with a mixture of $\mathrm{He} / \mathrm{N}_{2}$. Higher order harmonics were reduced by detuning the second monochromator to $40 \%$ of the maximum intensity. The XAS spectra were collected in fluorescence mode at the Pt $\mathrm{L}_{3}$-edge $(11.56 \mathrm{keV})$; a $3 \mathrm{~mm}$ thick $\mathrm{Zn}$ filter was used.

Five scans were collected for each compound in order to check for possible radiation damage, none was observed. The data were then averaged. The energy calibration was performed by setting the first derivative of the L3 edge of a Pt foil recorded in transmission to $11.564 \mathrm{keV}$. The spectra were normalized to the edge jump after removal of a linear background. Data reduction and analysis were performed with the Athena software.

\section{Results and discussions}

The 1,3-bis(2,6-diisopropylphenyl)imidazolium (IPr) chloride ligand was synthesized according to the previously reported procedure [43]. In order to obtain a Pt-IPr complex (1), the same method as in the synthesis of the analogous palladium complex was applied [18]. For this purpose, $\mathrm{PtCl}_{2}$ was reacted with the IPr imidazolium precursor in the presence of potassium carbonate in an excess of 3-chloropyridine.

While both $\mathrm{Pt}(\mathrm{II})$ and $\mathrm{Pd}(\mathrm{II})$ metal ions readily form square planar complexes, reactions on $\mathrm{Pt}(\mathrm{II})$ centres typically proceed many orders of magnitude slower compared to Pd(II) [49]. Therefore, TLC was used to monitor the progress of the reaction. After $48 \mathrm{~h}$, the desired Pt complex of PEPPSI type was formed. It is interesting to note that prolongation of the reaction time up to $64 \mathrm{~h}$ led to displacement of the carbene and formation of trans- $\mathrm{Pt}(3-\mathrm{ClPy})_{2} \mathrm{Cl}_{2}(2)$ complex as the thermodynamic product despite the strong Pt-carbene bond. Compound $\mathbf{2}$ is a known compound displaying crystal data in good agreement with the literature. The reactions are described in Scheme 1.

A single crystal X-ray diffraction experiment was performed and the molecular structure of complex $\mathbf{1}$ is given in Fig. 1. The geometry around the Pt(II) centre is as expected a slightly distorted square-plane with a trans arrangement of the two chlorine ligands and angles between cis-ligands ranging from $87.4(3)^{\circ}$ to $94.2(3)^{\circ}$. The NHC ring is situated at a $66^{\circ}$ angle to the coordination plane of $\mathrm{Pt}$, whereas the angle for the pyridine ring is $59^{\circ}$. The carbene C-Pt distance is 1.986(8) $\AA$ and the Pt-N 3-chloropyridine bond distance is $2.089(7) \AA$, which is in agreement with previously published data for similar complexes $[36,38,50]$.
Further information about the influence of the specific chemical environment around the metal ion on the electronic and geometric structures of $\mathbf{1}$ and $\mathbf{2}$ were obtained with XAS. Fig. 2 displays the Xray absorption spectra of $\mathbf{1}$ and $\mathbf{2}$ at the $\mathrm{Pt}_{2}$-edge. The inset zooms on the near-edge region and shows the FEFF 9.0 simulations for

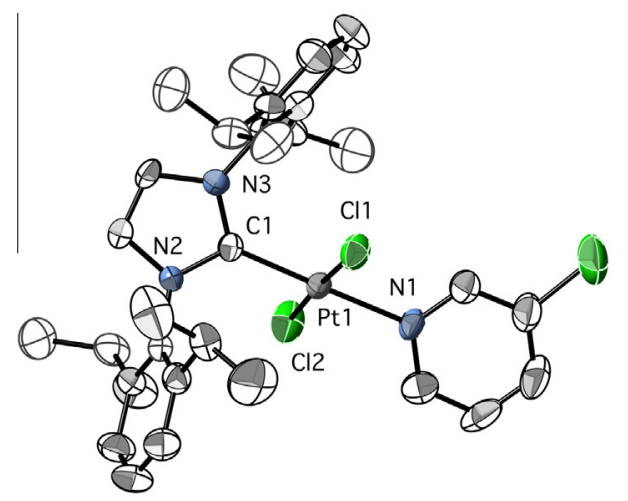

Fig. 1. Molecular structure of the compound 1. Hydrogen atoms omitted for clarity.

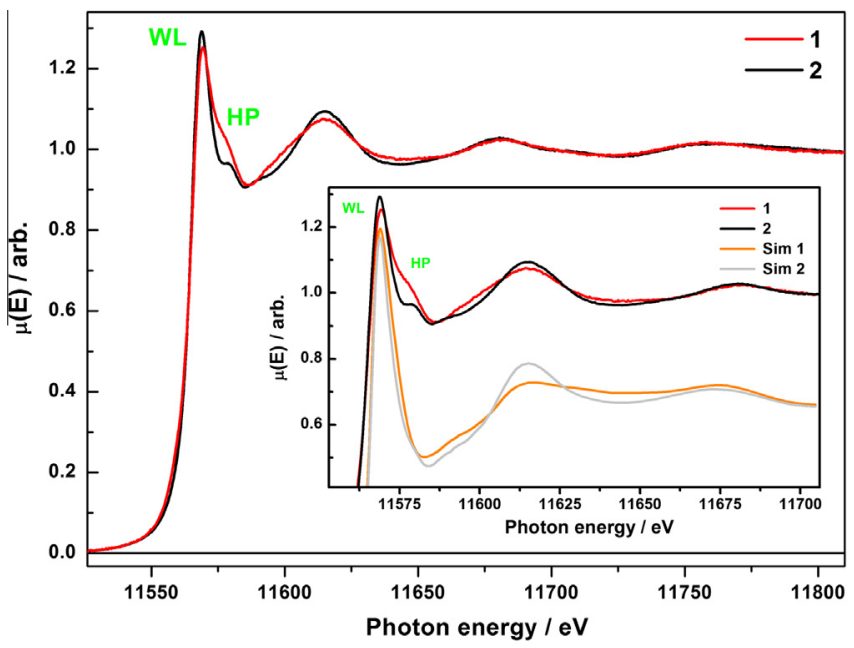

Fig. 2. Normalized X-ray absorption coefficient $\mu(E)$ for complex 1 (red) and 2 (black) at the $\mathrm{Pt}_{3}$ edge. The white line and the hybridization peak are indicated by WL and HP respectively. The inset zooms on the near-edge region and shows the FEFF 9.0 simulations for complex $\mathbf{1}$ (orange) and $\mathbf{2}$ (grey) based on the crystal structures, with an arbitrary offset in the y axis for clarity. (For interpretation of the references to color in this figure legend, the reader is referred to the web version of this article.)

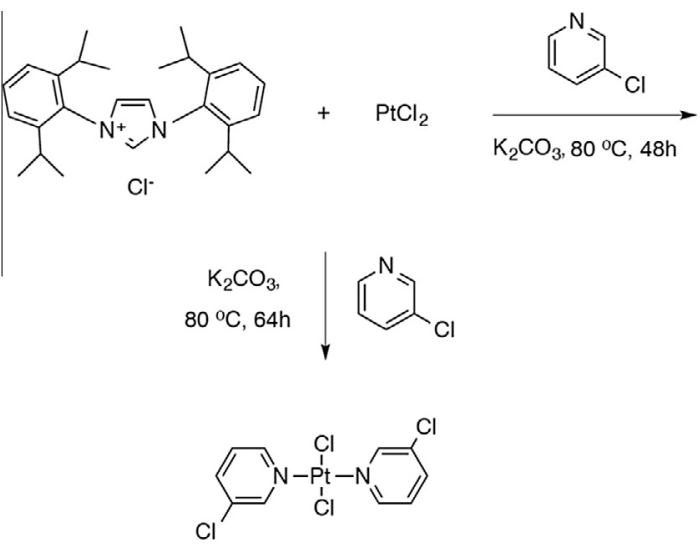<smiles></smiles> 
complex 1 (Sim 1) and $\mathbf{2}$ (Sim 2) based on the crystal structures, with an arbitrary offset in the $y$ axis for clarity.

We focused on the analysis of XANES region of the spectra due to its high sensitivity to the local binding environment around the particular absorbing atom. The first observable sharp spectral feature at the $\mathrm{Pt}_{2}$ edge (the so-called white line $(\mathrm{WL})$ ) is attributed to the dipole-allowed transition from Pt $2 \mathrm{p}_{3 / 2}$ to the unoccupied $5 \mathrm{~d}$ levels that lie above the Fermi level. It represents a rather precise fingerprint of the oxidation state of the Pt centre - the higher intensity of the spectral line is attributed to the higher oxidation state of the metal. Although precautions must be taken when comparing XAS measurements acquired at different beamlines, the XANES features for $\left[\mathrm{PtCl}_{4}\right]^{2-}[51]$ and 2 present some similarities. In both complexes, the Pt centre is in oxidation state +2 and they display a relatively sharp white line of comparable intensities with a maximum at $11567 \mathrm{eV}$ and $11562 \mathrm{eV}$ respectively. Replacing two chlorine atoms by two 3-chloropyridine ligands does not seem to alter the electronic distribution significantly despite the $\pi$-acceptor properties of the pyridine; such an effect may be weakened by the fact that the pyridine is not co-planar with the coordination plane and that electronic effects are known to be transmitted primarily in a trans fashion. However, a very small effect can possibly be seen in the crystallographic structure: the $\mathrm{Pt}-\mathrm{Cl}$ bond distances

Table 2

Selected bond lengths and angles for complex $\mathbf{1}$.

\begin{tabular}{llll}
\hline Bond lengths $(\AA)$ & & Bond angles $\left(^{\circ}\right)$ \\
\hline Pt1-Cl1 & $2.3153(15)$ & Cl1-Pt1-Cl2 & $176.67(6)$ \\
Pt1-Cl2 & $2.3062(16)$ & N1-Pt1-C1 & $177.8(2)$ \\
Pt1-N1 & $2.089(5)$ & $\mathrm{C} 1-\mathrm{Pt} 1-\mathrm{Cl} 1$ & $93.96(14)$ \\
Pt1-C1 & $1.984(5)$ & $\mathrm{C} 1-\mathrm{Pt} 1-\mathrm{Cl} 2$ & $89.36(15)$ \\
N2-C1 & $1.370(6)$ & N1-Pt1-Cl1 & $87.51(14)$ \\
N3-C1 & $1.366(6)$ & N1-Pt1-Cl2 & $89.18(14)$ \\
\hline
\end{tabular}

are known to be $2.310(2) \AA ̊$ for $\left[\mathrm{PtCl}_{4}\right]^{2-}$ [52] and 2.3001(9) $\AA$ for 2 [44]. In other words, the coordination of 3-Cl-pyridine causes a slight $\mathrm{Pt}-\mathrm{Cl}$ bond contraction.

On the other hand, comparing the shapes of the white line for $\mathbf{1}$ and $\mathbf{2}$ reveals the specific changes induced upon substitution of a 3-chloropyridine for the IPr carbene ligand. As seen in Fig. 2, the white line gets broader and less intense. The intensity of the WL reflects the unoccupied density of state at the $\mathrm{Pt}^{\mathrm{II}}$ centre $[53,54]$. Therefore, it can be deduced that the additional electron density associated with the strong $\sigma$-donor ability of the NHC ligand does not completely redistribute onto the trans-3-ClPy ligand, which results in a higher d-electron density at the Pt centre.

This observation can be correlated with the crystal data: the Pt-N of 3-ClPy is 2.089(7) $\AA$ in 1 instead of $2.015 \AA$ in 2, which is expected from the higher trans influence of the NHC ligand giving an additional effective charge on the $\mathrm{Pt}^{\mathrm{II}}$ centre.

The second noticeable feature in the XANES spectra is the shoulder found after the white line, the so-called hybridization peak (HP) [55]. It arises from a mixture between the Pt $\varepsilon$ photoelectron states of the outgoing photoelectron and the $\mathrm{Cl} 3 \mathrm{~d}$ unoccupied states. This hybridization is mediated by the multiple scattering paths that connect these two atomic sites (e.g. Pt-Cl-Pt and Pt$\mathrm{Cl}-\mathrm{Cl}-\mathrm{Pt}$ ). As seen in the inset of Fig. 2, HP is more diffuse for $\mathbf{1}$ than for 2. This mirrors the increased average $\mathrm{Pt}-\mathrm{Cl}$ distance of 2.311 (3) $\AA$ in 1, while it is only $2.3001 \AA$ in $\mathbf{2}$.

This comparative study shows that the XANES region at the $\mathrm{Pt}$ $\mathrm{L}_{3}$ edge is a sensitive spectral fingerprint of the Pt-NHC bond. As pointed out in the introduction, these markers can be followed in any physicochemical phase, hence operando. As such, it can clearly be applied to the diagnostic of the long-term hydrolytic durability of this type of complexes under catalytic conditions (see Table 2).

In order to evaluate the catalytic activity of this type of compounds, complex 1, obtained in this work, was tested as a catalyst in a range of ligand directed $\mathrm{C}-\mathrm{H}$ functionalization reactions

Table 3

$\mathrm{C}-\mathrm{H}$ functionalization of 4-(2-pyridyl)benzaldehyde.

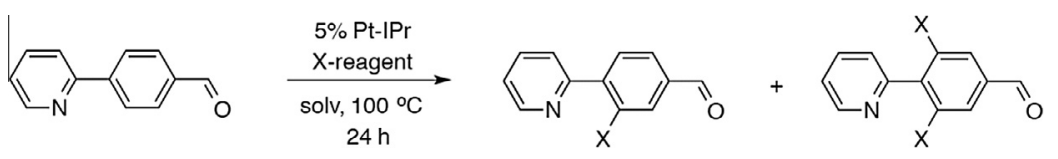

\begin{tabular}{|c|c|c|c|c|}
\hline X-reagent & Solvent & Catalyst (\%) & Time & Conversion \\
\hline $\mathrm{PhI}(\mathrm{OAc})_{2}$ & $\mathrm{MeCN}$ & 5 & 24 & 0 \\
\hline $\mathrm{PhI}(\mathrm{OAc})_{2}$ & $\mathrm{AcOH}$ & 5 & 24 & 0 \\
\hline NCS & $\mathrm{MeCN}$ & 5 & 24 & 0 \\
\hline $\mathrm{Ph}_{2} \mathrm{IPF}_{6}$ & $\mathrm{AcOH}$ & 5 & 24 & 0 \\
\hline
\end{tabular}

Table 4

Hydrosilylation of styrene.
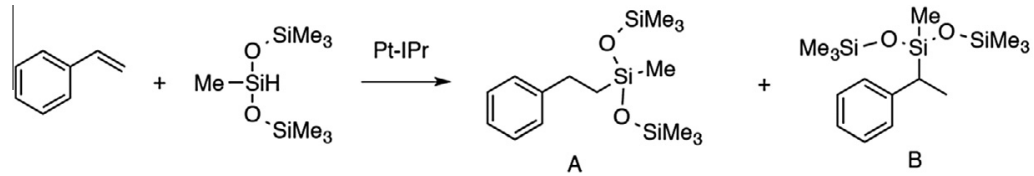

\begin{tabular}{|c|c|c|c|}
\hline Entry $^{\mathrm{a}}$ & $\mathrm{T}\left({ }^{\circ} \mathrm{C}\right)$ & Conversion (styrene) [\%] $]^{\mathrm{b}}$ & Ratio $\mathrm{A}: \mathrm{B}^{\mathrm{b}}$ \\
\hline 1 & 100 & 96 & $85: 15$ \\
\hline 2 & 140 & 87 & $87: 13$ \\
\hline
\end{tabular}

a Reaction conditions: $0.5 \mathrm{~mol} \%$ of catalyst, styrene ( $4 \mathrm{mmol})$, bis(trimethylsilyloxy)methylsilane ( $4.4 \mathrm{mmol}), 6 \mathrm{~h}$.

b Determinded by ${ }^{1} \mathrm{H}$ NMR spectroscopy. 
(Table 3) [56]. So far, palladium complexes have been overwhelmingly used as catalysts for such transformations, leaving ample space to investigate other metals. In a model reaction, 4-(2-pyridyl)benzaldehyde was reacted with $\mathrm{PhI}(\mathrm{OAc})_{2}, \mathrm{NCS}$ or $\mathrm{Ph}_{2} \mathrm{IPF}_{6}$ and $5 \mathrm{~mol} \%$ catalyst and heated at $100{ }^{\circ} \mathrm{C}$ for $24 \mathrm{~h}$. Unfortunately, no conversion of the starting material was observed.

Catalytic studies of the Pt-IPr complex performance were continued with a benchmark reaction of styrene hydrosilylation using bis(trimethylsilyloxy)methylsilane (Table 4) [36]. The hydrosilylation of carbon-carbon double or triple bonds employing platinum complexes is a well-known process for producing silicon derivatives on an industrial scale. Pioneering work in this field was done with highly active Speier and Karstedt catalysts [57,58]. Recently several platinum $\mathrm{N}$-heterocyclic carbene complexes were found to be active in this transformation showing excellent efficiency and selectivity $[36,38,59,60]$. We were pleased to find that the $0.5 \mathrm{~mol} \%$ of Pt-IPr complex catalyses up to $96 \%$ conversion of styrene to the products $\mathrm{A}$ and $\mathrm{B}$ at $100{ }^{\circ} \mathrm{C}$ after $6 \mathrm{~h}$ according to the NMR data. The ratio between the hydrosilane addition products A versus B was 85:15 respectively, which is within the same range as reported by Strassner et al. Increase of the reaction temperature to $140{ }^{\circ} \mathrm{C}$ led to a decrease of the styrene conversion and the formation of platinum black was observed.

\section{Acknowledgments}

We are grateful for support from the FP7 Marie Curie Actions of the European Commission, via the Initial Training Network SMALL (MCITN-238804), the Swedish Research Council, the Knut and Alice Wallenberg Foundation and the Royal Physiographic Society in Lund. S.E.C. acknowledges financial support from SFB 1073. We thank Dr. Alexey Polukeev for collecting the XRD data.

\section{Appendix A. Supplementary material}

CCDC 1441883 contains the supplementary crystallographic data for this paper. These data can be obtained free of charge from The Cambridge Crystallographic Data Centre via www.ccdc.cam.ac. uk/data_request/cif. Supplementary data associated with this article can be found, in the online version, at http://dx.doi.org/10. 1016/j.ica.2016.02.036.

\section{References}

[1] M.N. Hopkinson, C. Richter, M. Schedler, F. Glorius, Nature 510 (2014) 485.

[2] M. Melaimi, M. Soleilhavoup, G. Bertrand, Angew. Chem., Int. Ed. Engl. 49 (2010) 8810.

[3] H. Jacobsen, A. Correa, A. Poater, C. Costabile, L. Cavallo, Coord. Chem. Rev. 253 (2009) 687.

[4] F.E. Hahn, M.C. Jahnke, Angew. Chem., Int. Ed. Engl. 47 (2008) 3122.

[5] C.M. Crudden, D.P. Allen, Coord. Chem. Rev. 248 (2004) 2247.

[6] L. Mercs, M. Albrecht, Chem. Soc. Rev. 39 (2010) 1903.

[7] R. Visbal, M.C. Gimeno, Chem. Soc. Rev. 43 (2014) 3551.

[8] W. Liu, R. Gust, Chem. Soc. Rev. 42 (2013) 755.

[9] K.M. Hindi, M.J. Panzner, C.A. Tessier, C.L. Cannon, W.J. Youngs, Chem. Rev. 109 (2009) 3859.

[10] A. Kascatan-Nebioglu, M.J. Panzner, C.A. Tessier, C.L. Cannon, W.J. Youngs, Coord. Chem. Rev. 251 (2007) 884.
[11] H.D. Velazquez, F. Verpoort, Chem. Soc. Rev. 41 (2012) 7032.

[12] G.C. Fortman, S.P. Nolan, Chem. Soc. Rev. 40 (2011) 5151.

[13] C.S.J. Cazin, N-Heterocyclic Carbenes in Transition Metal Catalysis and Organocatalysis, 32, Springer, 2011. pp. 1-336.

[14] W.J. Sommer, M. Weck, Coord. Chem. Rev. 251 (2007) 860.

[15] E. Peris, R.H. Crabtree, Coord. Chem. Rev. 248 (2004) 2239.

[16] C. Valente, M. Pompeo, M. Sayah, M.G. Organ, Org. Process Res. Dev. 18 (2014) 180.

[17] C. Valente, S. Calimsiz, K.H. Hoi, D. Mallik, M. Sayah, M.G. Organ, Angew. Chem., Int. Ed. Engl. 51 (2012) 3314.

[18] C.J. O’Brien, E.A. Kantchev, C. Valente, N. Hadei, G.A. Chass, A. Lough, A.C. Hopkinson, M.G. Organ, Chemistry 12 (2006) 4743.

[19] S. Yaşar, Ç. Şahin, M. Arslan, İ. Özdemir, J. Organomet. Chem. 776 (2015) 107.

[20] D. Canseco-Gonzalez, A. Gniewek, M. Szulmanowicz, H. Muller-Bunz, A.M. Trzeciak, M. Albrecht, Chemistry 18 (2012) 6055.

[21] L. Ray, M.M. Shaikh, P. Ghosh, Dalton Trans. (2007) 4546.

[22] S. Calimsiz, M. Sayah, D. Mallik, M.G. Organ, Angew. Chem., Int. Ed. Engl. 49 (2010) 2014.

[23] M. Organ, G. Chass, D.-C. Fang, A. Hopkinson, C. Valente, Synthesis 2008 (2008) 2776.

[24] M.G. Organ, S. Avola, I. Dubovyk, N. Hadei, E.A. Kantchev, C.J. O’Brien, C. Valente, Chemistry 12 (2006) 4749.

[25] Y. Zhang, G. Lavigne, V. Cesar, J. Org. Chem. 80 (2015) 7666.

[26] Y. Zhang, V. César, G. Lavigne, Eur. J. Org. Chem. 2015 (2015) 2042.

[27] F. Wang, L. Zhu, Y. Zhou, X. Bao, H.F. Schaefer 3rd, Chemistry 21 (2015) 4153.

[28] A. Chartoire, X. Frogneux, A. Boreux, A.M.Z. Slawin, S.P. Nolan, Organometallics 31 (2012) 6947.

[29] M.G. Organ, M. Abdel-Hadi, S. Avola, N. Hadei, J. Nasielski, J. O’Brien, C. Valente, Chemistry 13 (2007) 150.

[30] K. Li, T. Zou, Y. Chen, X. Guan, C.M. Che, Chemistry 21 (2015) 7441.

[31] T. Zou, C.N. Lok, Y.M. Fung, C.M. Che, Chem. Commun. (Camb.) 49 (2013) 5423.

[32] E. Chardon, G. Dahm, G. Guichard, S. Bellemin-Laponnaz, Organometallics 31 (2012) 7618.

[33] R. Wai-Yin Sun, A. Lok-Fung Chow, X.-H. Li, J.J. Yan, S. Sin-Yin Chui, C.-M. Che, Chem. Sci. 2 (2011) 728.

[34] D. Brackemeyer, A. Herve, J. Am. Chem. Soc. 136 (2014) 7841.

[35] M.J. Geier, M.R. Gagne, J. Am. Chem. Soc. 136 (2014) 3032.

[36] M.A. Taige, S. Ahrens, T. Strassner, J. Organomet. Chem. 696 (2011) 2918.

[37] M. Lersch, M. Tilset, Chem. Rev. 105 (2005) 2471.

[38] G. Berthon-Gelloz, O. Buisine, J.-F. Brière, G. Michaud, S. Stérin, G. Mignani, B. Tinant, J.-P. Declercq, D. Chapon, I.E. Markó, J. Organomet. Chem. 690 (2005) 6156.

[39] L.J. Brennan, Organometallics 34 (2015) 2086.

[40] K. Machado, J. Mishra, S. Suzuki, G.S. Mishra, Dalton Trans. 43 (2014) 17475.

[41] M.P. Conley, C. Copéret, C. Thieuleux, ACS Catal. 4 (2014) 1458.

[42] N.E. Leadbeater, M. Marco, Chem. Rev. 102 (2002) 3217.

[43] A.J. Arduengo, R. Krafczyk, R. Schmutzer, Tetrahedron 55 (1999) 14523.

[44] F. Zordan, L. Brammer, P. Sherwood, J. Am. Chem. Soc. 127 (2005) 5979

[45] C.C.D. Crysalis, Oxford Diffraction Ltd, Abingdon, Oxfordshire, UK, 2005.

[46] R.E.D. Crysalis, Oxford Diffraction Ltd, Abingdon, Oxfordshire, UK, 2005.

[47] G.M. Sheldrick, SHELXTL, 5.1, Program for Structure Solution and Least Square Refinement, University of Göttingen, Göttingen, Germany, 1998.

[48] S. Carlson, M. Clausen, L. Gridneva, B. Sommarin, C.J. Svensson, J. Synchrotron Radiat. 13 (2006) 359.

[49] A. Sigel, H. Sigel, Metal Ions in Biological Systems, 32, CRC Press, 1996. pp. 1854.

[50] C.J. Adams, M. Lusi, E.M. Mutambi, A.G. Orpen, Chem. Commun. 51 (2015) 9632.

[51] T.K. Sham, J. Chem. Phys. 84 (1986) 7054.

[52] R.H.B. Mais, P.G. Owston, A.M. Wood, Acta Cryst. B28 (1972) 393.

[53] J.A. Horsley, J. Chem. Phys. 76 (1982) 1451.

[54] R. Ayala, E.S. Marcos, S. Diaz-Moreno, V.A. Sole, A. Munoz-Paez, J. Phys. Chem., B 105 (2001) 7588.

[55] A.L. Ankudinov, I.I. Rehr, S.R. Bare, Chem. Phys. Lett. 316 (5-6) (2000) 495.

[56] T.W. Lyons, M.S. Sanford, Chem. Rev. 110 (2) (2010) 1147.

[57] J.L. Speier, J.A. Webster, G.H. Barnes, J. Am. Chem. Soc. 79 (1957) 974.

[58] B.D. Karstedt, US Patent 226928, 1972.

[59] J.C. Bernhammer, H.V. Huynh, Organometallics 13 (2014) 172

[60] M. Poyatos, A. Maisse-Francois, S. Bellemin-Laponnaz, L.H. Gade, Organometallics 25 (2006) 2634. 